\title{
A New Demand-Supply Model to Enable Sustainability in New Australian Housing
}

\author{
Georgia Warren-Myers * (iD) and Christopher Heywood ${ }^{(D)}$ \\ Thrive, Faculty of Architecture, Building and Planning, The University of Melbourne, Melbourne VIC 3010, \\ Australia; c.heywood@unimelb.edu.au \\ * Correspondence: g.warrenmyers@unimelb.edu.au; Tel.: +61-3-8344-4325
}

Received: 18 December 2017; Accepted: 29 January 2018; Published: 31 January 2018

\begin{abstract}
Sustainability implementation in new housing in Australia lags much of the developed world's standards and implementation levels for residential sustainability. Various reasons for this are offered via a 'blame game' in a sector plagued by lack of demand, prohibitive costs, and poorly implemented existing energy efficiency regulations. Multiple gaps in traditional supply-led procurement theory inhibits sustainability's implementation in the Australian mass production residential construction system. Once-off consumers are not the key demand actor due to their inability to demand sustainability in a system that limits consumers' choice and demand. Warren-Myers and Heywood (2016) theorized that the mass-producing Volume Builders are the pivotal demand-side actor in mainstreaming sustainability in the Australian new housing system. This paper investigated the Volume Builders' roles and relationships with traditional demand-side actors, housing consumers, and the supply-side's subcontractors and suppliers, to identify the ultimate demand actor that drives the housing industry. The investigation used semi-structured interviews with Volume Builders. The results demonstrated Volume Builders' dominance of the Australian residential mass production construction industry validating their pivotal role as a demand-side actor in a consumption-based demand and supply model. This identifies Volume Builders as the key actor who could then drive wide-spread adoption of sustainability innovation in Australian mass-produced housing.
\end{abstract}

Keywords: residential construction; Australia; demand-supply model; demand-led innovation; sustainability

\section{Introduction}

In Australia, construction and utilization of the built environment account for $45 \%$ of annual energy consumption [1] and $18.1 \%$ of Australia's carbon footprint [2]. New housing accounts for much of this construction, suggesting a high imperative to implement more sustainability within the housing sector. More sustainable housing is required for the long-term environmental, social and economic benefits for current and future generations in Australia. Currently, sustainability in the Australian residential construction sector is limited to achieving minimum standards with varying levels of compliance [1], meaning that whether new homes are actually sustainable is questionable. With potentially poor levels of sustainability integrated into new housing, Australia lags the rest of the developed world in addressing this problem.

The Australian housing construction sector is dominated by Volume Builders. Volume Builders are large-scale state or national businesses serving several geographic regions. The Top 100 builders (by volume), account for $45 \%$ of new housing construction and the top 20 of which accounts for $57 \%$ [3]. Their domination increased by $8.5 \%$ in $2016 / 17$ and as housing construction starts to decline in the current economic climate, Volume Builders' continued growth strengthens their dominance 
of the sector. Volume Builders apply traditional design and construction procurement approaches on an industrial scale to mass-produce homes. This has resulted in an oligopoly of Volume Builders competing to attract customers that could be a barrier to, or change agent for, increased sustainability.

Increasing the sustainability of new Australian homes appears to be inhibited by theoretical and practical constraints in the system for creating and marketing homes. Five potential areas of theorization relate to the practical problem noted above and could provide ways forward but each has deficiencies [4]. One is that consumer theory makes the consumer the change agent through their demand for innovation, sustainability in this instance, and the supply part of the system should respond. Yet the catch cry of consumers 'won't pay' therefore we (Volume Builders) 'won't offer' is prevalent. Second is that construction procurement theory mimics consumer theory seeing the 'client' as the initiator of change. Third, the above suggests that applicable procurement model used in Australian volume home building—design and construct—appears to be part of the problem because of how actors are conceptualized and act in procurement. Fourth, construction procurement theory also largely focuses on non-residential construction. Fifth, when construction procurement theory examines residential construction it notes an industry structured through a plethora of micro-firms. Volume builders are rarely included in such theorization, nor what appears to be an evident oligopoly. This suggests a new approach to the system is required to break the evident impasse; an approach that reappraises industry structure and structural system dynamics. Establishing this new approach may allow more market-based means to be developed to mainstream sustainability which could sit alongside existing regulation-based approaches.

Warren-Myers and Heywood [4] theorize that the sector's industrialized traditional design and construct approach changes the demand and supply-side actors in the housing supply system in a way that could be important for mainstreaming sustainability (Figure 1). This challenges traditional views of who creates demand and drives change in housing. Traditional consumer theory suggests that the client or housing consumer drives change [5]. However, reports like Pitt \& Sherry [1] note that whilst plenty of blame for poor sustainability uptake is directed at consumers, consumer studies in new housing have identified that consumers lack power and knowledge, and thus face challenges in building new homes. In light of that, Warren-Myers and Heywood [4] suggest that Volume Builders play the critical role of the client within the supply chain, whilst housing consumers become customers or end-users. Therefore, both Volume Builders and consumers should be re-conceptualized as demand-side actors that have effects on system dynamics. However, the Volume Builders' power as a demand-side actor means they are, effectively, the client dictating the type of product produced. This suggests that the lever to increase sustainability in new Australian housing is actually through the Volume Builders, though traditional consumer and procurement theory does not support this. Mainstreaming sustainability in the industry may be assisted by demonstrating how the roles and relationships actually exist and operate within the volume housing sector, and who the ultimate demand driver is.

This research investigated actual Volume Builders' practice in Australia to validate Warren-Myers and Heywood's [4] theoretical framework that postulates the key role of volume builders in the demand and supply actors and relationships. This research addressed the theoretical gaps noted above by examining the different roles and relationships, and where the power drivers are within the framework. By ascertaining where the power is channeled, then potential for change and innovation to increase sustainability can be identified by isolating key drivers for the actors responsible for that change. The following section summarizes the existing theory and the previous establishment of the framework from Warren-Myers and Heywood [4]. This is followed by elaboration of the research methods and the results from the study. 


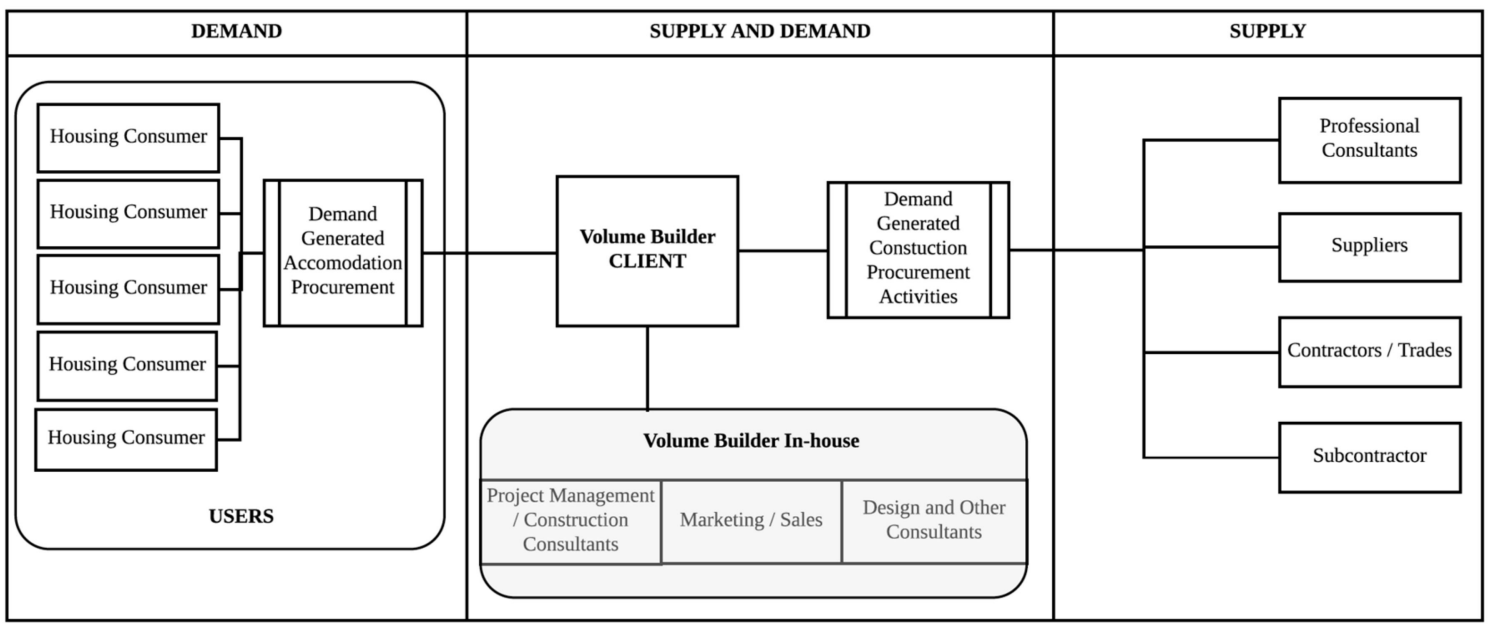

Figure 1. A framework for demand-supply players and relationships. After: Warren-Myers and Heywood [4], Figure 4.

\section{Examining the Theoretical Framework}

Construction procurement research focuses on the commercial sector. Predominately, this research is supply-side focused [6] with actor interactions also supply-side focused, namely material suppliers, manufacturers, trades, and product delivery [7]. When considering procurement in the residential housing context there are two main approaches in Australia; first, the Traditional approach, and, second, the Design and Construction approach.

The Traditional approach is where a housing consumer (homebuyer) approaches an architect or draftsman with a requirement and asks them to draw up plans for their dwelling. As shown in Figure 2, the architect's role is to communicate and effectively manage the other consultants and building contractors; but the contractual arrangements are directly between the housing consumer and the other actors.

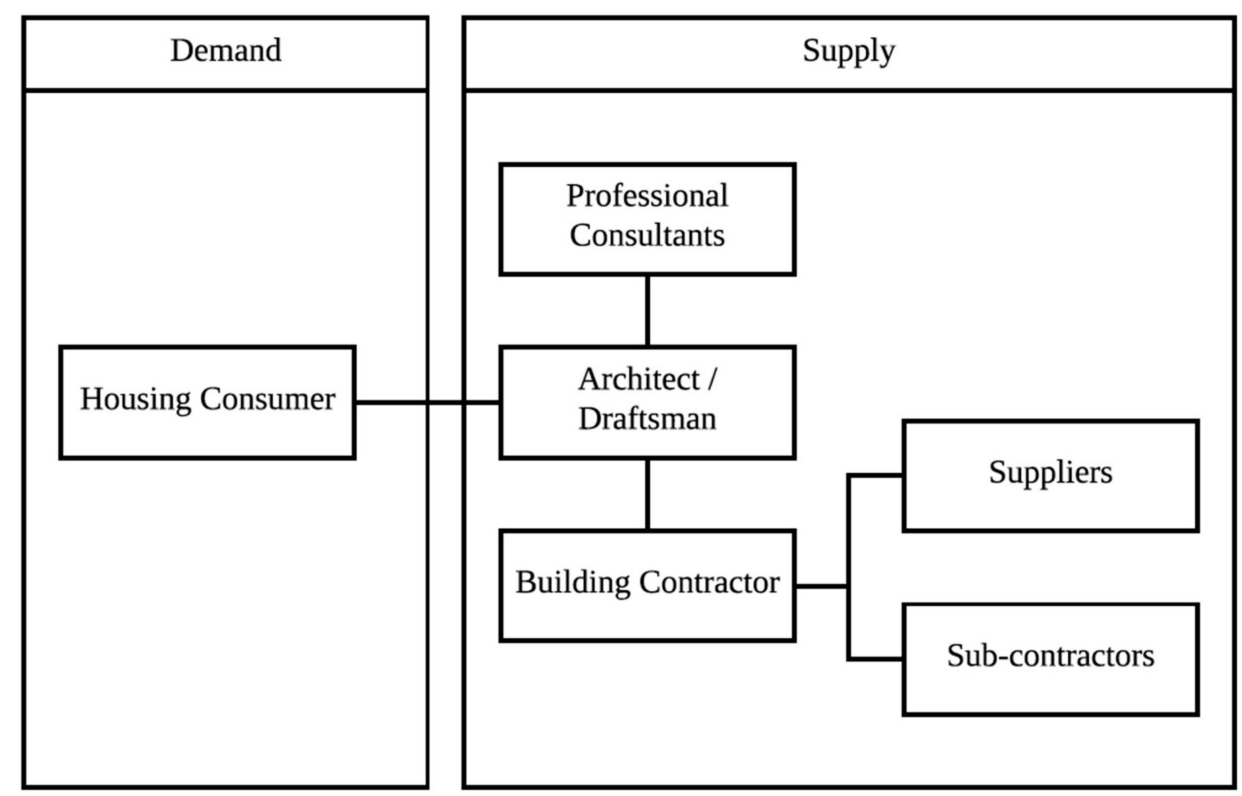

Figure 2. The traditional residential construction procurement approach. After: Warren-Myers and Heywood [4] Figure 1. 
The traditional approach has been fraught with issues of risk and responsibility resting with the housing consumer. It also only represents a small proportion of the new housing market. In Australia, this means that an alternative procurement process-the Design and Construct approach (Figure 3) -has become the mainstream approach to new home building in Australia.

The Design and Construct (D\&C) approach provides housing consumers with a 'one-stop-shop' - one contract with the risk predominately with the D\&C contractor and, essentially, a guaranteed end-product or result. D\&C procurement theory places the builder on the supply-side and provides a single contact point between the supply-side and the consumer as the source of demand. Design (architects or draftsmen) is either in-house or outsourced (Figure 3) with varying degrees of contact between the consumer and the designer. Variations in the D\&C residential model range from small contractors meeting localized demand (the traditional 'Master Builder' model) to large state or national business (Volume Builders).

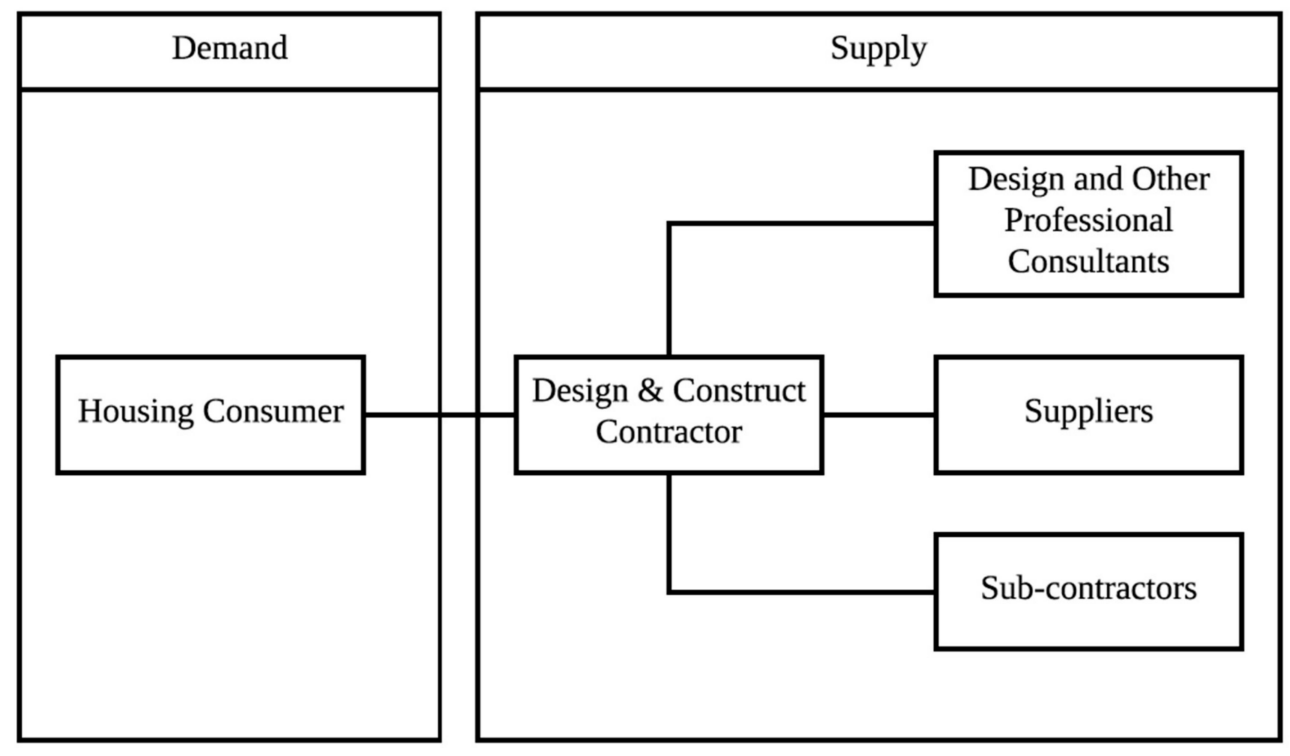

Figure 3. Design and Construct Approach. After: Warren-Myers and Heywood [4] Figure 2.

In Australia, D\&C has been industrialized into a process of mass production. It is becoming the main approach to home building with large Volume Builders as the dominant market actors. Over ten years the top 100 builders produced between $37 \%$ and $41 \%$ of all new housing [8,9], whilst the top 20 Volume Builders' share was typically between $56 \%$ and $61 \%$ and the top 5 produced $40 \%$ of the top 20's share; and this is increasing over time [8]. Within the Volume Builder system of mass producing dwellings, approaches vary slightly by type of product and production methods. Of all their dwellings built annually, $70 \%$ are detached homes, $9 \%$ are detached houses and $21 \%$ are multi-units which account for the rest [10]. Volume Builders also have a variety of company structures, size and type of operation. For example, there are community developers like Mirvac, Villawood, Stockland and Frasers; major project homebuilders like Metricon, Simmonds, Burbank and Henley Homes; medium-sized mass-produced home builders like Hotondo, Cavalier Homes, Now Homes and Pivot Homes.

Taken together, the characteristics noted above point towards an oligopoly [11], despite the plethora of small to micro-firms in the sector. Oligopolistic behavior is evident in the Volume Builder's ability to tell housing consumers what they want and how they want it, and they do this by providing limited choices to maximize efficiencies of scale and profits [12]. In Australia though, this is subtly disguised as marketing a 'lifestyle', as evidenced by trends in various additional features that have been offered over time. This paper does not seek to develop oligopoly theory, per se, but to record previously undocumented practices that appear to be oligopolistic. 
Typically, housing consumers buying from Volume Builders do two things. One, they select from a standard set of plans, often containing attractive 'features', with some choice in materials, finishes and options to entice them to build with the Volume Builders. This reflects the Volume Builders' dominant competitive strategy which is to create a standardized mass production model, whilst providing what appears to be a wealth of options to consumers [13,14]. Two, these infrequent purchasers with limited knowledge of residential construction processes are given a sense of empowerment while guiding them in their choices of dwelling, features, finishes and certainty of the price and product to be delivered $[13,14]$. These houses can be built as 'speculative' houses often as 'display homes' ahead of customer purchase or in response to customer orders [14].

Current supply-led D\&C theory assumes or treats each home purchase as a unique event with individual supply chains for creating the product. The practice of industrialized D\&C may not accurately reflect that theory. Australian Volume Builder's current practice of dwelling construction is shown in Figure 4. There is variance between the industrialized D\&C that comprises the approach displayed in the volume housing sector and the theoretical approach of $D \& C$ (changes discussed in $[9,15])$, as the element of multiple purchasers and the Volume Builder acting as an intermediary in the contracting process changes the dynamics in the relationships between the stakeholders. As previously discussed, (Figures 2 and 3) current practice makes Volume Builders suppliers of housing products procured by consumers. However, exploration of Volume Builders' relationships and interactions with other actors suggest that the supply and demand relationships are otherwise.

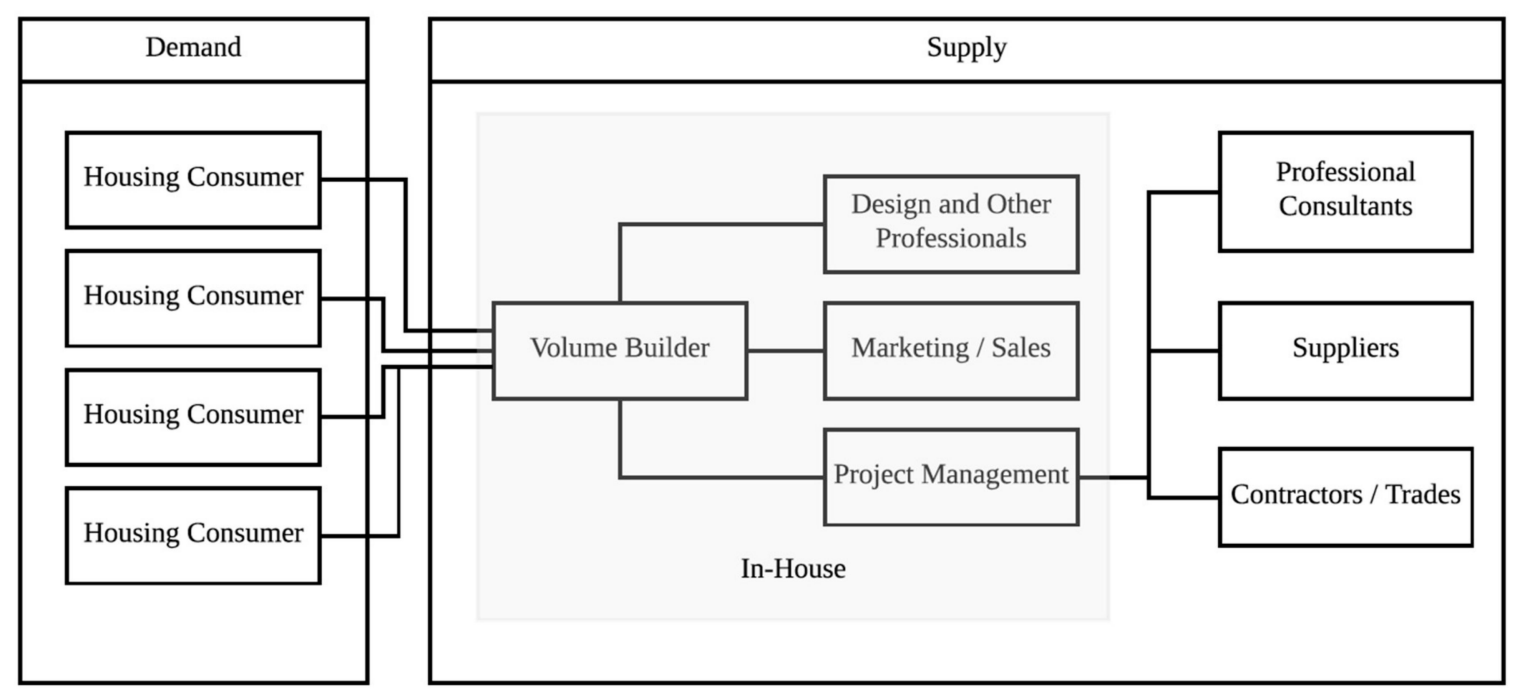

Figure 4. Australian Volume Builders' Current Practice. After: Warren-Myers and Heywood [4] Figure 3.

Volume Builders' size and market dominance means they can dictate to both consumers and the other supply chain actors. We have noted above the oligopolistic interactions with consumers that challenges assumptions about purchase uniqueness. With regard to their construction supply chain (up to 108 trades and suppliers exist in this supply chain ([14], Tables 3-9), Volume Builders' needs, requirements and to an extent price, command cost efficiency, quality and timely delivery from that supply chain. A power relationship is established in the contracts with their supply chain which are not for a single home, but for 100s or 1000s of homes. Consequently, for the trades and the suppliers (some of the many small businesses often noted as characteristic of the industry), this contract maybe their sole business. As a result, performing in terms of cost, quality and time is imperative to maintaining their contracts. The Volume Builders also have power in choosing suppliers and trades, with a few notable exceptions where some products have sole or limited suppliers, like Colorbond metal roofing material. Innovation and implementation coming from the supply side that would benefit 
increased sustainability is limited and the upwards push is often met with substantial limitations particularly in the aspect of knowledge transfer [16].

The established view of volume building as a D\&C process with the demand residing with the home purchaser and the Volume Builder a supplier has, to date, has been ineffectual for mainstreaming sustainable new housing, despite legislation requiring a 6 star Nationwide House Energy Rating Scheme (NatHERS). While the variety of issues regarding sustainability in new housing certification was detailed in Pitt \& Sherry [1]; an element of focus examined stakeholders' opinions as to why these issues occurred. What became clear was a 'blame game' was occurring with the blame being directed at consumers, who interestingly enough were not actually included in the study. Catch-cries of 'little or no interest from consumers', 'not a priority' and 'not willing to pay' came from many actors. Fundamentally, Australian consumers are blamed for the lack of more sustainable housing.

Consumer theory also suggests home purchasers are to blame, because an informed consumer creates demand to which the supply chain then responds. However, for consumers to be effective requires breadth (consumption creation and distribution) and intensity (volume, quality, and frequency) of engagement [17]. In contrast, a housing consumer is generally not knowledgeable about the building process, hence the choice of a Volume Builder; sustainability is not functional knowledge so they do not know what to ask for; purchasing a new house is generally a once-off activity; and for Volume Builders they are only one of many customers and generally not a repeat customer. Consequently, the home purchaser's ability to create and drive demand for sustainability products in the residential housing market is limited, despite the underpinning consumer theory.

Warren-Myers and Heywood's [4] examination of literature and analysis of the housing sector through analytical experience, theorized that industrialized residential construction realigned the traditional perspectives on demand and supply actors. Their framework for demand and supply actors and relationships as they exist in the Australian volume residential construction sector is based upon a consumption-based demand and supply model [18] interpreted through the D\&C procurement approach (Figure 1).

Contrary to traditional D\&C theory where Volume Builders are viewed as part of the supply chain; here Volume Builders are an actual client, and consequently, are considered a demand-side actor in addition to being a supply-side actor. Clients are project initiators [19], who 'prescribe the program, set the characteristics and define the ideal traits of what is yet to be produced' [20].

Warren-Myers and Heywood's [4] reflective theorizing of the relationships in new housing could potentially be useful in mainstreaming sustainability, as the key change agent can be isolated and initiatives driven through them. However, validation is required to establish whether it is a viable model of the industry and whether it can act as a potential basis for system changes to increase the implementation of sustainability in new housing in Australia. Following that validation, it would then be possible in future work to examine how the existing industry approaches sustainability and how the new demand-supply model could be used in increasing sustainability in Australian new housing.

\section{Materials and Methods}

The purpose of this paper is to investigate the roles and relationships of actors in the Australian new housing industry to clearly demonstrate if the framework introduced above is applicable to the Australian residential construction sector. The research questions are:

1. Who is the ultimate demand actor that drives the housing industry?

2. How do the roles, responsibilities and relationships between the actors clarify who are the demand-side actors?

This study used audio recorded semi-structured interviews with 18 Volume Builders as key actors within the industrialized home building system from types of firms including speculative builders, order builders and franchise order builders [21]. These 18 participants represent $55 \%$ of the top 20 builders, $32 \%$ of the top 50, and $18 \%$ of the top 100 . The following codes are used for 
builder types and individual respondents. For the speculative builders, they are coded SPEC (1 to 4); for order builders ORD (1 to 11) and for franchise order builders FOR (1 to 3). Research ethics approval was obtained through the University of Melbourne Human Research Ethics Committee and ethics protocols were maintained during the project, ensuring that all participants are anonymous. Ethics was approved 1 June 2015 and project identifier code is: 1544599.1.

The Volume Builders were asked questions regarding the perceived roles and relationships with their customers and suppliers. This also included process-mapping where participants graphically depicted and described their organizations, roles and responsibilities [22]; their contractual, product and customer relationships; and the flow of information and power associations. This shows, on analysis in Nvivo, the various structural relationships in their procurement models and identifies how innovation and change are currently enabled through residential housing industry mechanisms. Data saturation was clear with the Volume Builders across the interviews responding in a very similar fashion. Differences were noted depending on the builder type and their perception as to who the ultimate driver was.

There were four speculative builders who provide pre-planned dwellings, often as part of an integrated product from a development; for example an apartment, townhouse or house and land package, which were commonly sold off-the-plan and in most cases, there are only very limited options or selections available. Eleven order builders were interviewed, who generally provide homes to consumers' orders from a standard set of plans, with options regarding facades and finishes and upgrade options. Finally, three franchise order builders were interviewed, who operate in a similar manner to the order builders but are generally smaller firms who operate under a national brand name, which allows for greater efficiency in marketing, product development, documentation, materials and trade suppliers. There were also two builders interviewed that considered themselves sustainable or green builders, one being a franchise builder and the other an order builder. However, these are not reported here because of the focus on Volume Builders and these participants did not fit that category. With the exception of these two builders, all of the builders interviewed were listed in the Housing Industry Association Top 100 home builders.

\section{Results}

The following section is ordered as follows:

- Results relating to the standardized, mass-production system in which Volume Builders operate. This includes reference to results about competitiveness within the system;

- Results pertaining to the centrality of Volume Builders to the mass production system. This is structurally shown in their diagrammatic representations of the system, and influentially with regard to both their relationships with customers and their construction supply chain; and

- Results on how this system deals with innovation with a view to understanding how the theoretical framework provided could aid the uptake of sustainability.

This examination of roles and responsibilities will allow conclusions to be developed regarding Volume Builders' client-ness' to show Volume Builders as the ultimate point of demand in the standardized, mass-production volume building system and the key leverage point for sustainability innovation.

\subsection{Products and the Standardised Mass-Production System}

The analysis confirms suggestions (for example, $[4,13]$ ) that Volume Builders create a standard set of plans that can be mass produced. These comments about their product types were common and examples included: "mass produced homes" (ORD1); "set of architecturally designed homes produced on mass scale approach with a limited number of plans" (ORD7); "pre-designed, pre-costed solution/package for customers" (ORD9); and "we offer all standard 'franchise' houses" (FOR1). Speculative Builders had an unalterable approach and clearly demonstrated their role as the client, as their products were 
completely defined in terms of the type of product they offered. Choices are limited to choosing a three, four or five-bedroom home; color schemes internal and external; and potentially some upgrade features, for example: "Mass production ... detached housing low and medium density housing — non-lifted ... always part of a house and land package" (SPEC3); and "We create three styles of product as -it's all residential of course ... blocks of land ... townhouses ... apartments" (SPEC2).

Volume Builders, other than the speculative builders, provide a sense of empowerment to the housing consumer by offering what appears to be a wealth of choices of dwelling, features, finishes and a certainty of price and product that will be delivered. This product needs to be 'packaged' in a way that provides a cost-effective home that feels like there is plenty of choices. As ORD7 and ORD8 reflected on the sales process, "(it's) a 'menu' driven plan, providing a set of plans for standard houses" and "It reminds me of that cheesy American franchise sales process, step by step take the client through. By the time they are done they are exhausted and they've bought more than they thought. They knew that, so they are getting into it knowingly ... but people (Volume Builders) are selling on price".

Varying from this standardized product can lead to steep additional costs, for example, "the product would comprise a base level price plus upgrades, which are specified by the builder. Any options or changes after, even just a power point would incur a minimum \$1500 charge" (ORD8). Here, Volume Builders use monetary mechanisms to control consumers' choices. Volume Builders are not ignorant of consumers, as FOR2 notes, "we sell a home, and the home is the most expensive investment in a consumer's lifetime". In practice, Volume Builders understand that consumers are seeking a 'dream home' and subsequently this provokes a marketing approach that results in Volume Builders marketing and selling a lifestyle. For the Volume Builders who operate as speculative builders, like SPEC1, the production of housing comprises the designing, building and development of that dwelling without further, or any direct input from housing consumers. Yet they do undertake substantial consumer market research into purchasers' wants, needs, and desires, and rate themselves as one of the best at this. It is clear from a speculative builder's perspective that the product is clearly defined, designed and built to their specifications; invoking Tombesi's [20] and Warren-Myers and Heywood's [4] classification that a speculative builder operates as a sophisticated client, whilst the consumer or home purchaser is clearly a customer choosing a specified product. In essence, this suggests that certainly the speculative builders operate as a key demand-side actor, whilst the supply chain comprises suppliers, sub-contractors, trades and the like.

\subsection{Competing for Consumer Spend: The Relationship between Consumer and Volume Builder}

As mentioned by the Volume Builders, their central role makes them the prime conduit; it also emphasizes their position as the client, who is designing and developing a product for a customer. The 'packaged' product or 'menu-driven plan' provides a cost-effective home that feels like there are plenty of choices which is capitalized on by the Volume Builders to compete against each other. The competition between the Volume Builders is fierce, and the sales process is designed to attract and engage the consumer and get them to sign, "(the housing market) is driven by the Volume Builders competing with each other ... if you pick up the Saturday Herald Sun which is very strongly aimed at the Volume Builder promotion thing, it's all about the finish, the look, the price" (ORD2). One of the key elements in marketing to consumers is the cost, as for "Home buyers this is (their) largest investment, most home buyers will only build one home" (ORD5) and "Most customers will only ever build one house so it's not like you're going to have the ability to have multiple runs at it and figure it out. So, if a builder tells you something and says this is what you should do, customers are usually more than happy to do it" (FOR2).

Customers' sensitivity to cost is a major issue in building a home; and cost will likely be a primary factor that will drive decision making; yet they place their trust in the builders to provide the best solution for them. The problem is that many consumers are going through the building process for the first time and their inexperience and expectations of product and cost can be inversely proportioned. For example, "I think where a lot of the educated customers come unstuck is that they don't really have any understanding on the budget implications of what they're talking about" (ORD3); and "often have people 
come and they've got all these great ideas and it's like well that's great, we'll get the builder to price it out for you but where's your budget expectation at" (ORD4); and "home buyers don't know what they want. Customers might think they know what they want, but they don't really. Consequently, you need to undertake this process for them. They have no idea about what is required in a home" (ORD8). However, in driving cost as a key consideration and the main competition factor, the Volume Builders appear to lose their focus on customer satisfaction and education. Although several did mention their approaches to try and maintain and build stronger relationships with customers; the general approach would be that once signed and committed the relationship with the customer is of little importance. Yet there are differences between SPEC builders and ORD builders. The SPEC builders seem to have a higher desire to appease the customer throughout the process, and believe their reputation has a strong role in repeat business and broader industry reputation; consequently, they talked of having special processes set up to communicate with the consumers throughout the build with pictures and sometimes walk-throughs. Whereas the ORD builders seem to lose interest in the purchaser once the contract is signed, which was clearly described by ORD8 who outlined the communication process between the Volume Builder and the customer. Firstly, trust and "rapport built" between the customer with the sales team through the initial meetings and discussions. In guiding through the options and choices with the sales team, once the customer signs the contract, the sales team's job is complete and the customer is effectively handed over to the administrative and construction teams where "they are just a number and a file". As the customer has been handed on, the key contact person or person in which the consumer trusts, the sales agent, is "no longer in control ... nor do they (consumer) have any relationships with the administrative and construction teams." So the "excitement for the consumer dissipates because they become a file, the lack of personal attention and connection to the project is lost ... dissatisfaction ebbs in." Many decisions are still required during the construction phase, yet the loss of trust and communication channels challenges both sides, with the consumer being more skeptical of the builder and the builder just wanting to get the job done.

The Volume Builders are very aware of the need to engage the consumer to design and create a product that will 'sell'; yet are sensitive and understand the competitive requirements to maintain a 'cheap' or 'value-laden' price tag to get customers to sign. There is a mismatch in terms of expectations by the Volume Builders needing numbers and wanting to minimize cost, and the customer wanting a personalized experience whilst achieving value for money. The Volume Builders relationship with their customers appears to be initiated through the sales team, then once a contract is signed the relationships are either maintained by proactive volume builders (usually the speculative builders) or customers become effectively a 'number' and connection is lost. The relationship, whether continued and sustained throughout the project or not, is more a result of the actions of the Volume Builder than the customer.

\subsection{The Central Role of the Volume Builder}

Warren-Myers and Heywood [4] theorized the central role of the Volume Builder in the industrialized Design and Construct approach that is evident in Australian new residential construction. The evidence here showed the dominance of Volume Builders regarding both the traditional demand-side actor, the customer (consumer), and the supply-side actors of the supply chain. A selection of diagrams drawn by the different respondents (Figures 5-7) highlights their centralized role in the process. An example from each of the different builder types are included to demonstrate that although the product type varies, fundamentally their relationship with customers/consumers and supply-side actors are similar, and they see themselves as a central conduit between the customer and the supply side. 


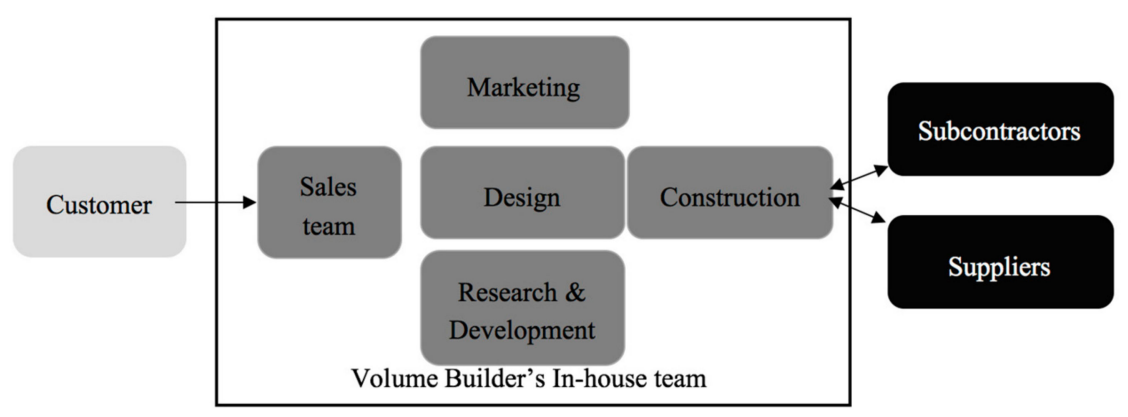

Figure 5. ORD8 process map.

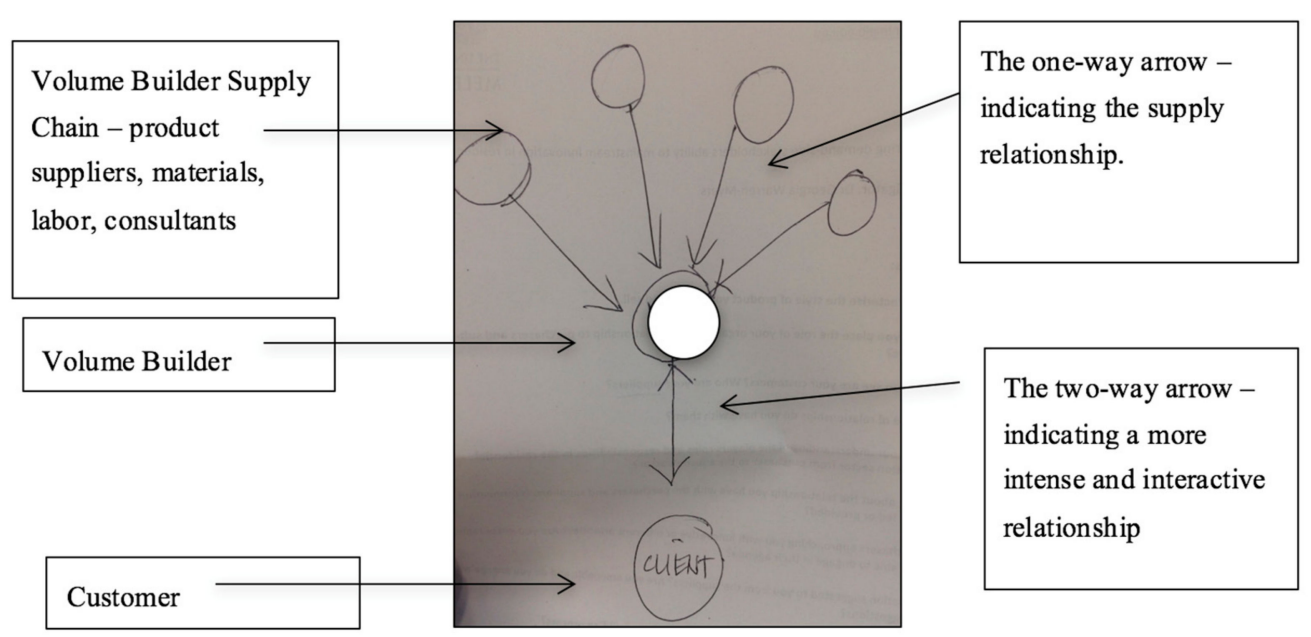

Figure 6. SPEC 3's process map.

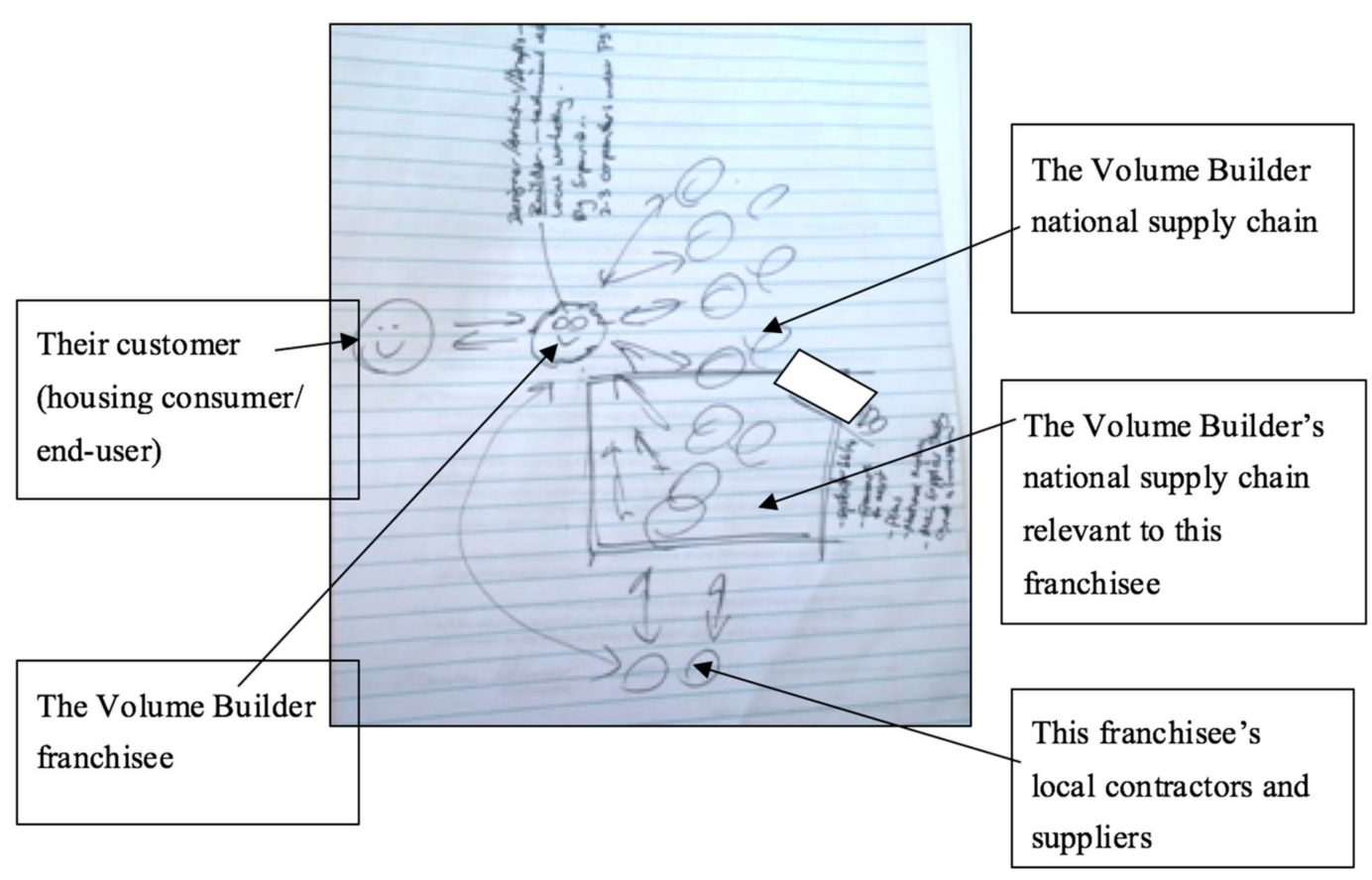

Figure 7. FOR1 process map. 
The Volume Builder's central role was made clear by all respondents, as highlighted by FOR2; "it's pretty simple, where basically the customers are on one side and we're in the middle and then on the other side is all the products and trades and stuff like that". A key element that was mentioned multiple times was the Volume Builders' central role as the key and only contact with the customer. Whilst any communication with the supply side is only with the Volume Builder, it is clearly articulated that the customers have no relationship or communication with any of the suppliers, trades or subcontractors. This is solely the role of the Volume Builders to communicate and work with the supply side actors, for example "We would see ourselves as being, if you like, the center ... then you have the customer base above, and then a supply chain and authorities over here" ... "we become a facilitator in effect, to create the outcome for these customers to consider to buy" (SPEC2).

\subsection{The Role of the Consumer}

With the centrality of the Volume Builder now established structurally, their relationships and degree of influence with both the customer and the supply chain need detailed examination. First, the role of the customer. The Volume Builders adopt a dual approach to their customers. The first approach is to create a product of desire or desirable features, and a lifestyle that is both affordable yet still standardized in order to achieve their efficiencies of scale and profit margin. The second approach is to team this with marketing techniques to engage and encourage customers to commit to a product purchase.

An example of the first approach: "(the) Objective is to provide a customer-focused process that engages the customer but still provides a standardized project-that is pre-designed, pre-costed and will provide a premium process for the customer experience" (ORD9). There is a strong focus on market research and understanding the customers, "So our role is about understanding who the end resident would be, how they would live in an environment, what's a day in the life?" (SPEC2); "we do a lot of market research" (ORD1); and from reflecting on their built product "when you sell that number of houses you get a lot of intelligence out of that number of houses (about what customers want)" (ORD2). This seemed particularly strong amongst the speculative builders: "we respond to the desires, wants, needs of customers, whether they know what they are or not. Sometimes we are anticipating for the customer, through signals, if you like, about what they might want" (SPEC1). As a second approach, the use of marketing techniques to engage and encourage customers to commit was demonstrated by ORD8, "The sales team also focus on trying to create a sense of urgency in the purchasing process-this 'luxury' package it's only available till Sunday, you've got to sign today and you can guarantee your price and package. Using a fear-based marketing tactic that focuses on "missing out". Further ORD9 details how the sales process is focused on tactics to get the customer to sign up which is strongly related to the type of product that is 'standardized' for the organization, as "They (Volume Builders) stick to that model of, we build this. We (Volume Builders) know how much it costs to the dollar. We are going to do the same sales pitch and try and get as much as we can once we engage with the client. That's the whole objective, get them in" (ORD9).

A difference in expertise between the Volume Builders and their customers was noted. "Most customers will only ever build one house so it's not like you're (the customer) going to have the ability to have multiple runs at it and figure it out (the building process). So, if a builder tells you something and says this is what you should do, customers are usually more than happy to do it" (FOR2). While cost will likely be a primary factor driving customer's decision making, a flow-on effect of the expertise gap was the degree of trust customers placed in the Volume Builders to provide the best solution for them. The problem is that many consumers are going through the building process for the first time and their inexperience and expectations of product and cost can be inversely proportioned. However, as noted above the competition for customers section, the cost driven competition factor meant that the Volume Builders appeared to lose their focus on customer satisfaction and education once the initial contract was signed. Which further challenges the experience of the consumer to be engaged in the process and their satisfaction levels subsequently deteriorate (ORD8). The consumer is clearly in a position of weakness in their relationship with Volume Builders, and as a result, generally have limited capacity to 
demand substantial changes or to initiate the drive for alternative solutions, like sustainability, as they are strongly guided by the mandate and offerings of the Volume Builders.

\subsection{The Role of the Supply-Side}

In relation to the supply-side supply-chain, identified here as the suppliers, sub-contractors, trades and the like, the Volume Builders also wield an enormous amount of power in terms of relationships, requirements and play an integral role in the level of innovation in the sector. $\mathrm{D} \& \mathrm{C}$ theory currently presumes a unique, singular contractual relationship between the housing consumer and the builder, with numerous contracts with the various supply-chain actors [23]. This was apparent in all the interviewees' figures (selection is above in Figures 5-7); of a direct singular contract, and generally at the beginning engagement directly with a sales team, but no interactions with draftspersons, architects or the construction team on the supply side.

The evidence here indicates that although relationships could be represented in a way consistent with current theory as exemplified by Wilkinson and Schofield [23]; there is a suggestion that Warren-Myers and Heywood [4] theory and the Volume Builders' power is apparent, in that Volume Builder supply-chain contracts are generally not for a singular dwelling (project) but for potentially many dwellings. This representation of multiple contracts for numerous homes (rather than one-off builds) with the supply chain was clearly described by the Volume Builders. There were variations in how the contracts were defined between the different groups; for example, the speculative builders' contracts were generally large once-off contracts for, say, several hundred homes. Others had agreements for a certain number of products for so many homes at an agreed price from a supplier, but individual purchase orders would be issued for each home; "The standardized process ensures a buying power with the suppliers and contractors. Custom builders lack the strength of buying power because they have to tender every project and from a supplier perspective they may or may not get the job, consequently the dollar value of the contract is not substantial for them to focus or make an effort to achieve to provide an efficient cost, and the risk of the one-off project is factored into the price." (ORD8). ORD10 notes that all their main suppliers "The big ones like CSR, the Borals; we've got the window manufacturing company; we've got timber frames and flooring joist companies; that's at the structural level, providing us bricks, tiles" have large major contracts for large quantities of products. ORD 3 made very similar observations about suppliers.

The speculative builders took a similar but more nuanced approach and suggested how the relationships might differ in comparison to an order builder; "I would like to think that our national procurement model means that we get cost efficiencies... I think there are others that produce a more homogenous product that may get better volume discounts than us (like the order builders)" (SPEC1). This suggests that the contracts are large, and as a result, better purchasing power is achieved, for both speculative and order builders. Although SPEC1 did not that quality difference might also be a consideration in terms of production selection and quality, as "They (order builders) may be happy to only get seven out of ten, on the product in order to get the cheaper volume discount, whereas we would probably want the eight or nine out of ten, and recognize that it maybe costs us a little more, but we've got a more satisfied customer that might buy off us again and will maybe pay a slightly better price" (SPEC1). Across the Volume Builders purchasing power appears to be achieved through products, even for the franchisees. The franchisees like FOR1 and FOR2 discussed the benefits of their Franchise's purchasing power though there were instances of using local suppliers and trades (see Figure 7); “There are the big suppliers like James Hardie or Dow, the big organisations, they have relationships with head office (Franchiser), and those deals are done between (Franchiser) and those big suppliers, and then we benefit from the buying power that has been negotiated" (FOR1). FOR3 also identified benefits from using national hardware chains like Bunnings to bulk order certain items. Where costs across regions varied widely their national profile provided a convenient and cost-effective solution.

There can be a sense of partnership and getting value for money from the relationships; “there's also some partners will give us a special rate. So, if we agree to at least use their product where possible, 
they'll give us a special rate to make it more appealing for the builders, and those sorts of situations usually work well" (ORD3). Franchise builder FOR2 indicated that contracts and relationships are revisited every two years and renegotiated. Both FOR1 and FOR2 also maintained that, where in their control, they used local trades and suppliers "We are very local orientated" (FOR2). Often these were long-term relationships with "the electrician for 30 years" (FOR1). The "relationships are key (with subcontractors)" (SPEC2) and "The relationship we have is very long-term generally with all of our consultants" (SPEC3) suggesting that strong relationships are evident across the types of Volume Builders with this quality and assurance of long-term commitment also mentioned by SPEC3. Consequently, this highlights the transfer of the power balance to the demand side, as the Volume Builders can dictate to an extent their requirements to the supply chain actors.

The Volume Builders resoundingly state that, effectively, cost drives the industrialized approach to construction. Order builder, ORD11, states "The construction side is all about the cost base" going on to discuss that the power is over the suppliers because Volume Builders have a good indication and are able to anticipate how many homes they will build; unlike the custom builders where every project is different and individual pricing is required. By using the standardized housing plans and approaches the Volume Builders enjoy substantial buying power with the suppliers and contractors, achieving greater cost savings in the process and increasing margins. This suggests that through mass production, they can achieve strength in buying power but also minimize cost and be able to provide affordable housing for consumers.

\subsection{Driving Force in the Sector-Who Are the Ultimate Drivers in the Relationship?}

The Volume Builders were asked to reflect on who was the ultimate driver in the relationships with customers and the supply-side actors. Resoundingly, all believe they are the central drivers of the industry, for example, "I guess the ultimate drive in the building process, I suppose we are" (FOR2). Further, it was noted that the standardized approach to building was not new as "our market is dominated by some standard practices that have been going on for decades, simply because they're so standardized" (FOR1). Yet there is limited research into the residential volume housing market, in particular exploring the dominant role Volume Builders play in the market, though the Volume Builders are certainly aware of their own power and dominance within the sector.

Four aspects were self-identified by the Volume Builders that point to themselves as the key driver. These were also evident in the results above but are re-emphasised and summarised here in their own words:

- Influence over the consumer:

"We (the Volume Builders) are really the guys that have the greatest influence over what it is that people have available to consider" (SPEC2); and "Look, builders have so much power over customers, it's insane. We don't wield that in a negative way, but I guarantee, and I tell you for that right now that many builders do use that to their advantage. Customers are like putty in your paws sometimes as a builder. They take so much advice on-board from builders as gospel and just go with it" (FOR2):

- The decisions about the product made by the Volume Builder:

"From us, because we're the builder and the designer and the developer, yes, we are. We do drive it. Because we're the designer and the developer, we-it's on our shoulders if the customers don't want to buy it or they don't like it when they get it, and we're also the designer, so we've got to have the conscious thought about that. So, yeah, we definitely drive that side of things" (SPEC1); and "Yes, on balance. It's us, because, at the end of the day, we have to draw and make a decision about what the customer's going to want. So, yeah, it probably is-some of it comes back from the supplier, but generally it's from us" (SPEC4);

- The directing of product at the consumer:

"In terms of product to the purchaser, we see ourselves as the driver. We will come up with a scheme, we're very hands-on coming up with a scheme or a potential scheme based on what previous clients and projects 
have told us." (SPEC3); and "certainly when it comes down to the nitty-gritty of the homebuilding itself, we probably — the builders, as a group, would be the main driver. In terms of provision of the product to the purchaser" (ORD7); and

- The role of Volume Builders as a driving sector in terms of their size and also their impact on the broader economy:

"we are the drivers in the industry, and I think we're all quite responsible in being such a big force" (ORD10); and "I think we are certainly the big drivers in the industry, and also responsible for a big chunk of the economic activity" (ORD11).

\section{Discussion}

The Australian home building sector seems resistant to the wide-spread adoption of sustainability innovation for a variety of reasons [1]; reasons which include issues primarily with housing consumers' ability to demand through willingness to pay for such innovation and the construction supply chain's capacity to 'push up' innovation into more sustainable housing. However, much previous work is limited because it only examines part of the system rather than the whole. This suggests that a new whole-of-system perspective is required, particularly for mass-produced housing which is a significant proportion of new Australian residential construction. The framework validated here provides such a whole-of-system view.

Innovation in the form of increased sustainability in new homes provided benefits to both the consumer and the Volume Builder in their demand-side roles as customer and client [4]. The customer has economic, environmental and social benefits from a more sustainable dwelling over its life. The Volume Builder should be able to utilize sustainability as a marketing edge to attract more homeowners to their product and as part of a 'lifestyle', an approach they already use. Having demonstrated the roles of customer and client and the power wielded by the Volume Builder, this paper reports on Volume Builders' perspectives on innovation and sustainability and whether this is directed by them or whether it is a result of customer demand or supply-side suggestions.

New home consumers are often characterized as being the ones with the power to demand innovation or sustainability [1], as is consistent with consumer theory [5,24]. However, in the case of new housing, to drive that demand-side they need to be informed and have the capacity to make those decisions [4]. Yet, as noted earlier, being once-off home purchasers it is unlikely that home consumers are informed and knowledgeable of the process and the new home product. Consequently, their ability to make choices that can lead to change is limited. As noted above, the Volume Builder acts the role of a sophisticated client. From the Volume Builders perspective "home buyers don't know what they want. They have no idea about what is required in a home. Consequently, innovation or change is provided by the Volume Builder or housing provider in this process" (ORD8) and "our customers are not architects or builders, and they are not as close to the detail as we are, and most people can't read plans, for example" (ORD1). Ultimately, they trust the builders to make the decisions for them, and trust that this is in their best interests "When someone's buying from us, they are trusting that we have done all of the thinking about the design. They are entrusting a lot of that with us" (ORD1).

Further, if purchasers try to innovate, Volume Builders actually prevent this by effectively outpricing the product and making it appear too expensive. For example, "Sometimes purchasers will ask and come up with ideas, however it would appear from our (Volume Builders) perspective they are off-put by the price tag that will be attached" (ORD7); "if buyers want to change anything there is a hefty price tag involved to discourage change" (ORD8); and "Customers are given options but not too many. If they want something-I know that we say, we can do anything you want, but we don't make it feasible for the purchaser. They know that it's going to cost a bit more. We discourage that" (ORD2). In essence, from the Volume Builders' perspective, they already deliver the required product, they have researched the market, they are the informed participant so consequently, customers should not need to change anything; "the idea is that they won't need to change anything, because of the design process we have gone through. At present we are going through expansive customer analysis and design concepts to ensure we are meeting the demand" 
(ORD9) and "we like to think we are good at gathering and understanding customers' desires, needs and ideas ... Process and technology, in terms of build and design, really that comes from us-often it comes from problem-solving within a project team, and the customers have almost nothing to do with it" (SPEC1).

Thorpe et al. [16] suggested that supply-side innovation is limited and the upwards push from it is often met with resistance. This is particularly so in the aspect of knowledge transfer. Here, it was discovered that suppliers tend to approach the Volume Builders to display new products. However, the engagement with the product was variable, unless the Volume Builder saw a direct reason for including the product or suggestion; "with the bigger suppliers, they know that the marketplace is very competitive, and we also know it's very competitive. Within five, six months of any new idea that comes through, everybody picks it up and has their own variation of [such] materials or finishes or whatever. So, yes, we like to talk to our suppliers, and they do also come and offer some of the new things that they may be coming up with, and we barter with them to showcase it in our display homes." (ORD7); and "Many product suppliers like CSR and these guys are out there trying to find ways to innovate and stay relevant, come up with new products. We're always talking to them to know what they're doing, what their futures are" (SPEC2). Occasionally the take-up varied from the suggestion: "Sometimes people will come to us-suppliers will come to us with a product-something that they've come up with and they actually think it's for something but we actually will use it for something else" (SPEC4).

What was clear though, was that supply-side innovation came out of need for market share, through competition: "We work very closely with our suppliers to make sure that we-I mean, we've got to be ahead of the market. So if Metricon comes and they've got robed doors and we haven't got the same sort of robe doors, then, all of a sudden we lose market share" (ORD1). More often, the Volume Builder took the initiative for innovation and would contact the supply-side actors to seek their advice and whether they could supply and at what price: "Most of the time it's (innovation) actually more provided and the innovation's got to come from us" (SPEC4) and "we're not wedded to all those things and if we want to try something different, we'll tell them what we know about it and we'll look further if we have to" (FOR1). SPEC1 indicated they approached supply-side actors with a 'problem' rather than general requests for innovation. Innovation would evolve from problem-solving rather than directly seeking 'innovative' ideas: "we talk a lot about innovation. SPEC1 has an award-winning innovation program, but my honest view is, if you put a group of people in a room and say, go innovate, nothing happens. If you put a challenge in front of a project team, and say, get over that mountain, they will innovate to get around that mountain or get over that mountain." This was often teamed with a competitive outlook by Volume Builders where they are using innovation as "a marketing advantage for us and it's driven further innovations" (SPEC4).

However, many Volume Builders indicated that if the innovation's product quality or price did not satisfy their requirements, then they would not use the product and would continue seeking appropriately priced or quality services or product. In this case, the Volume Builders can dictate their requirements, be it an innovative solution in the design and construction process, or a sustainability initiative; but it is up to the supply chain to supply the product at a price and quality acceptable to the Volume Builder, otherwise the Volume Builder will choose a different supplier or provider. As "in general, we in the industry still largely are fairly formal in that just a contractual relationship between us-the supplier gives you something that you ask for, and you use it in the way that you did the time before. But there is some dialogue between the two" (SPEC1).

So, it appears that innovation could be pushed from the supply-side, and there is suggestion some of this occurring particularly where the Volume Builders see competitive or cost-based advantage, or have a problem that needs solving, but it is not significant in driving innovation. It is clear from this investigation that Volume Builders see themselves as the gate-keepers to innovation on both the customer and supply chain sides. If any innovation occurs it is at their directive and they make it happen. Consequently, this suggests that if significant change in the industry is to occur, it needs to come from the Volume Builders. Sustainability queries with the Volume Builders indicated a once-off attempt here or there. Catch cries of 'it doesn't work', and 'customers won't pay' were common. However, if mandated across a housing product, rather than an add-on or additional cost and used in 
terms of marketing themselves in the industry, this may change their opinions. Opportunities lie in using their power within the system as documented here to offer innovative lifestyle products and in driving sustainability innovation in their supply chains.

The Volume Builders interviewed exhibited approaches to home building consistent with the theoretical framework by Warren-Myers and Heywood [4]. They all agreed on the relationship between the consumer and Volume Builder; and the relationships between the Volume Builder and the construction procurement actors. They agreed that while the consumers sought out their business, they (the Volume Builders) had ultimate control of the process, with contracts with various suppliers and contractors utilized to build more than one dwelling. Their supply-side contracts were large and significant. In this, it was confirmed that their role made them a demand-side actor, rather than being purely a supply-side actor. All participants identified the housing consumer as the user of the product. However, they were not the only actor on the demand-side, as all Volume Builder participants clearly identified themselves as being, essentially, the client in the process, whilst the consumer was their customer as the end-user seeking a finalized product/package in the form of a completed dwelling. This contrasts with usual theory that the housing consumer is essentially both the user and the client (see for example $[23,25,26])$. This research supports Tombesi's [20] classification of clients and here the housing consumer is the Volume Builder's customer and is the end user, choosing a 'known' product from a selection which only indirectly affects supply products through preference selection.

\section{Conclusions}

This paper validates the proposed residential mass production, consumption-based demand and supply framework [4] and provides a whole-of-system perspective representing current practice in the Australian residential construction sector. This could then be used as a basis for driving wide-spread adoption of sustainability innovation in volume housing.

The Volume Builders' responses tested this framework demonstrating its applicability in the context of mass production of new housing. It represents the current roles and responsibilities of the different actors and who the power drivers are. Further, it provides a basis on which to argue for its usefulness in mainstreaming sustainability innovation in new housing. It is applicable for several reasons. First, it shows the Volume Builders' traditional theoretical positioning as a supplier of housing. This study's Volume Builders' housing supply was restricted to standardized designs with limited opportunity for the consumer to create demand for other option other than from a controlled set of options. Second is that it shows supply occurring within a D\&C procurement system with a supporting construction supply chain. In the Volume Builders' construction procurement, the assumption in D\&C theory of unique supply chains for each construction contract was varied with supply-side contracts with the Volume Builders applying over multiple houses and for the franchisees, multiple franchises. A third reason is that the framework shows Volume Builders at the central position in the demand-supply system at the overlap between the demand and supply sides, a position that becomes crucial in the innovation argument. In that position, the Volume Builders not only supply to consumers but also generate demand from the supply chain. This makes them the crucial client in the system.

This central position is the key structurally and also influentially through power dynamics in the Volume Builders' demand-supply arrangements. From this knowledgeable position and with the restricted product offering Volume Builders have a power to shape products supplied to consumers. From their contracting position with supply-side actors, generally being small to medium-sized operators, they have power over what is demanded from their supply chains. With this demand-supply framework formally showing the whole-of-system relationships and from knowledge of power dynamics, it can now be argued that Volume Builders are the keystone from where the drive for sustainability innovation needs to occur. Therefore, Volume Builders can create innovative, truly sustainable housing products and generate a latent demand that uses Australian housing consumers' propensity to pay for a perceived lifestyle, to take up a more sustainable lifestyle. It is also the 
place to demand improved products and construction practices to deliver the innovative, sustainable housing products.

Using this paper's demand-supply framework to change the perspective on achieving sustainable new housing shows opportunities for using the oligopoly's power in mass-produced housing to drive widespread market change through the system. Often this has been the basis of regulation-driven approaches in the past where it was thought that more stringent rules for builders will result in greater amounts of more sustainable housing. Pitt \& Sherry [1] show that this regulation-driven approach is not succeeding. A demand-supply approach utilized here suggests a more market-focused approach could be useful. There is the capacity and ability to drive a more innovative, sustainable product into the marketplace without necessarily incurring additional cost, providing a product that looks and feels the same as current conventional housing but is significantly more sustainable. The Volume Builders' strong relationships, contractual and financial power over the supply-side actors means that should Volume Builders take the opportunity to mainstream sustainability into their housing products, the supply chain will then need to respond. The size and power of the Volume Builders means they can enable cost-efficient solutions due to contract sizes and volume of houses. This should mean that issues identified by homebuyers, like cost-effectiveness and quality of workmanship and product, can be achieved through the actions of the Volume Builders in mainstreaming sustainability.

\section{Limitations and Future Research}

This research examined industry structures and dynamics that can be barriers to mainstreaming sustainability in Australian new home construction. It is generalizable within this context, though other countries may find comparable circumstances should similar work be undertaken there. Within Australia, the sampling suggests that good levels of generalization of the industry are achieved and that the framework provides a good model of the industry. It is also evident that additional research would be beneficial into oligopolistic practices in the construction industry that is peripherally noted here.

The research established the validity of the framework and the possibility that it could be used in mainstreaming sustainability. To establish that possibility's veracity requires further evidence of existing Australian Volume Builder approaches to sustainability and evidence of how this new understanding could be used. There is insufficient space here to adequately deal with this and so, for now, must remain future research.

Acknowledgments: This research was funded by the Faculty of Architecture, Building and Planning (University of Melbourne) Early Career Researcher Grant and a contribution from the Faculty towards the publication costs.

Author Contributions: Georgia Warren-Myers conceived, designed and conducted the research and the draft of the paper. Christopher Heywood contributed to the research idea and development of the theoretical framework and revised drafts of the paper providing feedback and comments.

Conflicts of Interest: The authors declare no conflict of interest.

\section{References}

1. Pitt \& Sherry. National Energy Efficiency Building Project. Department of State Development-Government of South Australia, Adelaide. 2014. Available online: http://dpc.sa.gov.au/what-we-do/services-forbusiness-and-the-community/energy-efficiency/national-energy-efficiency-building-project (accessed on 23 July 2017).

2. Yu, M.; Wiedmann, T.; Crawford, R.; Tait, C. The Carbon Footprint of Australia's Construction Sector. Procedia Eng. 2017, 180, 211-220. [CrossRef]

3. Housing Industry Association. Housing 100 2016/17; Housing Industry Association Economics: Campbell, Australia, 2017.

4. Warren-Myers, G.; Heywood, C. Investigating demand side stakeholders' ability to mainstream sustainability in residential property. Pac. Rim Prop. Res. J. 2016, 22, 59-75. [CrossRef] 
5. Spaargaren, G.; Oosterveer, P. Citizen-Consumers as Agents of Change in Globalizing Modernity: The Case of Sustainable Consumption. Sustainability 2010, 2, 1887-1908. [CrossRef]

6. Love, P.; Skitmore, M.; Earl, G. Selecting a suitable procurement method for a building project. Constr. Manag. Econ. 1998, 16, 221-233. [CrossRef]

7. O'Brien, W.; London, K.; Vrijhoef, R. Construction supply chain modeling: A research review and interdisciplinary research agenda. ICFAI J. Oper. Manag. 2004, 3, 64-84.

8. Dalton, T.; Chhetri, P.; Corcoran, J.; Groenhart, L.; Horne, R. Understanding the Patterns, Characteristics and Trends in the Housing Sector Labour Force in Australia; AHURI Positioning Paper No. 142; Australian Housing and Urban Research Institute: Melbourne, Australia, 2011.

9. Dowling, R. Residential Building in Australia 1993-2003. Urban Policy Res. 2005, 23, 447-464. [CrossRef]

10. Housing Industry Association. Housing 100 2014/15; Housing Industry Association Economics: Campbell, Australia, 2015.

11. Coiacetto, E. Real Estate Development Industry Structure: Is It Competitive and Why? Research Paper 10; Urban Research Program Griffith University: Brisbane, Australia, 2006.

12. Reardon, C. Buying a Home off the Plan. Your Home. Available online: http://www.yourhome.gov.au/ (accessed on 20 February 2015).

13. Barlow, J.; Childerhouse, P.; Gann, D.; Hong-Minh, S.; Naim, M.; Ozaki, R. Choice and delivery in housebuilding: Lessons from Japan for UK housebuilders. Build. Res. Inf. 2003, 31, 134-145. [CrossRef]

14. Dalton, T.; Wakefield, R.; Horne, R. Australian Suburban House Building: Industry Organisation, Practices and Constraints; AHURI Positioning Paper No. 142; Australian Housing and Urban Research Institute: Melbourne, Australia, 2011.

15. London, K.; Kenley, R. An industrial organization economic supply chain approach for the construction industry: A review. Constr. Manag. Econ. 2001, 19, 777-788. [CrossRef]

16. Thorpe, D.; Ryan, N.; Charles, M. Innovation and small residential builders: An Australian study. Constr. Innov. Inf. Process Manag. 2009, 9, 184-200. [CrossRef]

17. Labrecque, L.; vordemEsche, J.; Mathwick, C.; Novak, T.; Hofacker, C. The Evolution of Consumer Empowerment in the Social Media ERA: A Critical Review. In Ideas in Marketing: Finding the New and Polishing the Old; Karjaluoto, H., Ranaweera, C., Jayawardhena, C., Fredrikson, V., Eds.; Springer International Publishing: Ruston, LA, USA, 2015; pp. 582-582.

18. Heywood, C.; Kenley, R. An integrated consumption-based demand and supply framework for corporate real estate. In Proceedings of the 2010 International Conference on Construction and Real Estate Management, Brisbane, Australia, 1-3 December 2010; China Architecture and Building Press: Brisbane, Australia, 2010.

19. Atkin, B.; Flanagan, R. Improving Value for Money in Construction: Guidance for Chartered Surveyors and Their Clients; Royal Institution of Chartered Surveyors: London, UK, 1995; ISBN 0854067078.

20. Tombesi, P. Good thinking and poor value: On the socialization of knowledge in construction. Build. Res. Inf. 2006, 34, 272-286. [CrossRef]

21. Warren-Myers, G.; McRae, E. Volume Home Building: The Provision of Sustainability Information for New Homebuyers. Constr. Econ. Build. 2017, 17, 24-40. [CrossRef]

22. Harry, B.; Sturges, K.; Klingner, J. Mapping the process: An exemplar of process and challenge in grounded theory analysis. Educ. Res. 2005, 34, 3-13. [CrossRef]

23. Wilkinson, S.; Schofield, R. Procurement systems for construction projects. In Management in the New Zealand Construction Industry; Pearson Education: Auckland, New Zealand, 2003; pp. 239-249.

24. Solomon, M.R.; Russell-Bennett, R.; Previte, J. Consumer Behaviour: Buying, Having, Being; Pearson Australia: Frenchs Forest, Australia, 2013; ISBN 978-1-442-55358-3.

25. Boyd, D.; Chinyio, E. Understanding the Construction Client; Blackwell Publishing Ltd.: Oxford, UK, 2006; ISBN 978-1-405-12978-7.

26. Love, P. Influence of project type and procurement method on rework costs in building construction projects. J. Constr. Eng. Manag. 2002, 128, 18-29. [CrossRef]

(C) 2018 by the authors. Licensee MDPI, Basel, Switzerland. This article is an open access article distributed under the terms and conditions of the Creative Commons Attribution (CC BY) license (http:/ / creativecommons.org/licenses/by/4.0/). 